\title{
Erratum to: Update of guidelines on laparoscopic (TAPP) and endoscopic (TEP) treatment of inguinal hernia (International Endohernia Society)
}

\author{
R. Bittner ${ }^{1} \cdot$ M. A. Montgomery ${ }^{2} \cdot$ E. Arregui $^{3} \cdot$ V. Bansal ${ }^{4} \cdot$ J. Bingener $^{5} \cdot$ \\ T. Bisgaard ${ }^{6} \cdot$ H. Buhck ${ }^{7} \cdot$ M. Dudai ${ }^{8}$ - G. S. Ferzli ${ }^{9}$ - R. J. Fitzgibbons ${ }^{10}$ \\ R. H. Fortelny ${ }^{11}$ - K. L. Grimes ${ }^{3}$ - U. Klinge ${ }^{12}$ - F. Köckerling ${ }^{13}$ - S. Kumar ${ }^{4}$. \\ J. Kukleta ${ }^{14} \cdot$ D. Lomanto ${ }^{15} \cdot$ M. C. Misra ${ }^{4} \cdot$ S. Morales-Conde ${ }^{16} \cdot$ W. Reinpold ${ }^{17}$. $^{16}$.

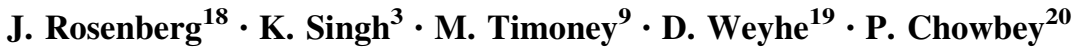 \\ Published online: 21 March 2015 \\ (C) Springer Science+Business Media New York 2015
}

\section{Erratum to: Surg Endosc (2015) 29:289-321 \\ DOI 10.1007/s00464-014-3917-8}

The name of the 14th author F. Koeckerling is misspelled.

The correct spelling is F. Köckerling.

The online version of the original article can be found under doi:10.1007/s00464-014-3917-8.

\section{R. Bittner}

bittnerfamilie@web.de

1 Hernia Center, Winghofer Medicum Plus, Röntgenstr. 38, 72108 Germany

2 Section of Laparoscopy and Abdominal Wall Reconstruction, Department of Surgery, Skåne University Hospital, 20502 Malmö, Sweden

3 Advanced GI Surgery, Laparoscopy, Endoscopy and Ultrasound, St. Vincent Hospital and Health Care Center, 8402 Harcourt Rd. Suite 815, Indianapolis, IN 46260, USA

4 Division of Minimally Invasive Surgery, Department of Surgical Disciplines, All India Institute of Medical Sciences, Angari Nagar, New Delhi 110029, India

5 Division of Gastroenterological and General Surgery, Mayo Clinic, 200 First Street SW, Rochester, MN 55905, USA

6 Gastro Unit, Surgical Section, Hvidovre Hospital, University of Copenhagen, Copenhagen, Denmark

7 Med Comm Tools, Hildesheimer Str. 13, 30169 Hannover, Germany

8 Department of Surgery, Ramat Aviv Medical Center, Tel Aviv, Israel
9 Department of Surgery, Lutheran Medical Center, SUNY Health Science Center, Brooklyn, 65 Cromwell Avenue, Staten Island, NY, USA

10 Department of Surgery, Creighton University, 601 North 30th Street, Suite 3700, Omaha, NE, USA

11 Department of General, Visceral and Oncological Surgery, Wilhelminenspital, 1171 Vienna, Austria

12 Surgical Department, University of Aachen, and Institute for Applied Medical Engineering AME Helmholtz, Pauwelstrasse, 52074 Aachen, Germany

13 Department of Surgery and Center for Minimally Invasive Surgery, Vivantes Hospital, Neue Bergstr. 6, 13585 Berlin, Germany

14 General, Visceral, Abdominal Wall Surgery, Klinik Im Park, Grossmuensterplatz 9, 8001 Zurich, Switzerland

15 Minimally Invasive Surgical Center, KTP Advanced Surgical Training Center, YYL School of Medicine, National University Hospital, Kent Ridge Wing 2, 5 Lower Kent Ridge Road, Singapore 119074, Singapore

16 Advanced Laparoscopic Unit of the University Hospital "Virgen del Rocío", General, Digestive and Laparoscopic Surgery Unit of the USP-“Sagrado Corazón” Clinic, University of Sevilla, Seville, Spain 
17 Department of Surgery, Gross-Sand Hospital Hamburg, Gross-Sand 3, 21107 Hamburg, Germany

18 Department of Surgery D, Herlev Hospital, University of Copenhagen, Copenhagen, Denmark

19 Department of Surgery, Pius Hospital, Georgstrasse 12, 26121 Oldenburg, Germany

20 Minimal Access, Metabolic, and Bariatric Surgery, Max Healthcare Institute Ltd., 2 Press Enclave Road, Saket, New Delhi, India 